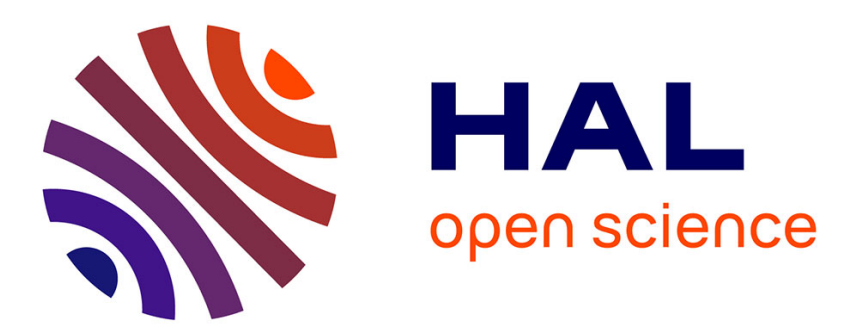

\title{
Active emitters based on nanostructured Si
}

F. Gourbilleau, A. Belarouci, D. Bréard, C. Dufour, R. Rizk

\section{To cite this version:}

F. Gourbilleau, A. Belarouci, D. Bréard, C. Dufour, R. Rizk. Active emitters based on nanostructured Si. International Journal of Nanotechnology, 2008, 5 (6/7/8), pp.574-591. 10.1504/IJNT.2008.018683 . hal-01826455

\section{HAL Id: hal-01826455 \\ https://hal.science/hal-01826455}

Submitted on 29 Jun 2018

HAL is a multi-disciplinary open access archive for the deposit and dissemination of scientific research documents, whether they are published or not. The documents may come from teaching and research institutions in France or abroad, or from public or private research centers.
L'archive ouverte pluridisciplinaire HAL, est destinée au dépôt et à la diffusion de documents scientifiques de niveau recherche, publiés ou non, émanant des établissements d'enseignement et de recherche français ou étrangers, des laboratoires publics ou privés. 


\title{
Active emitters based on nanostructured Si
}

\author{
F. Gourbilleau*, A. Belarouci, D. Bréard, \\ C. Dufour and R. Rizk
}

CIMAP, UMR CNRS, CEA, ENSICAEN, Universite de Caen, 6 Bd Maréchal Juin, 14050 Caen Cedex, France

E-mail: fabrice.gourbilleau@ensicaen.fr

E-mail: ali.belarouci@ensicaen.fr

E-mail: david.breard@ensicaen.fr

E-mail: christian.dufour@ensicaen.fr

E-mail: richard.rizk@ensicaen.fr

${ }^{*}$ Corresponding author

\begin{abstract}
The present paper deals with the use of Si-nanoclusters as efficient sensitisers for $\mathrm{Er}$ and $\mathrm{Nd}$ rare earth ions or as active emitters in $\mathrm{Si} / \mathrm{SiO}_{2}$ Fabry-Perot microcavities. The films have been fabricated using the reactive magnetron sputtering of a silica target. The energy transfer efficiency from $\mathrm{Si}-\mathrm{nc}$ towards $\mathrm{Er}$ ions has been studied as a function of the fabrication parameters (hydrogen rate, annealing temperature) through time resolved PL intensity measurements on Er-doped silicon-rich silica layers. A multilayer approach has been developed to determine the critical parameters such as the optimum Si-nc size and the characteristic interaction distance Si-nc-Er ions which govern the transfer Si-nc-Er. Thus we have found an optimum size of $4 \mathrm{~nm}$ for the Si nanocluster and a maximum spacing of $0.4 \mathrm{~nm}$ between the $\mathrm{Si}$-nc sensitisers and the $\mathrm{Er}^{3+}$ ions. First results on the efficient sensitising effect of Si nanocluster towards $\mathrm{Nd}^{3+}$ ions are also reported. Concerning the optical planar $\mathrm{Si} / \mathrm{SiO}_{2}$ microcavities, spectral, spatial and temporal photoluminescence behaviour of the $\mathrm{Si} / \mathrm{SiO}_{2}$ multilayers confined inside the resonator are studied. The comparison with a reference sample evidences the effect of the distributed Bragg reflectors structure on the intensity enhancement and the directional characteristic of the emission.
\end{abstract}

Keywords: reactive magnetron sputtering; rare earth; $\mathrm{Si}$ nanocrystal; microcavity.

Biographical notes: Fabrice Gourbilleau received the $\mathrm{PhD}$ in Physics from the University of Caen (France) in 1993. Since 1994 he has been in a permanent researcher CNRS position at the Structure des Interfaces et Fonctionnalité des Couches Minces (SIFCOM) laboratory, Caen, France and heads the «Integrated Nanostructure for Microelectronics and Photonics» group. He works on the effects and properties of nanoscaled materials since 1990 . He has more recently focused his research on the fabrication by magnetron sputtering and characterisation of nanostructured silicon-based thin films for photonic or microelectronic applications. He has been engaged in several EU and national projects dealing with laser, photovoltaic and photonics applications. He is the author and co-author of more than 80 papers and the 
holder of one patent. He is the Representative of the Nanosciences for the Region Basse Normandie and is involved in the Transfer of Technology Society for the Creation of Start-Up.

Ali Belarouci obtained his $\mathrm{PhD}$ in 1999 at the University of Lyon and is currently Research Scientist at the CNRS. His studies concentrate on mesoscopic devices including silicon nanocrystals and rare earth ions. $\mathrm{He}$ also worked on waveguide nano-optics devices for applications in optical communication and memory (three years at Montana state University, USA), and on light localisation in nano-cavities (18 months at $\mathrm{MESA}^{+}$Institute, The Netherlands).

David Bréard became Engineer from the ENSICAEN Engineering School in 2004. He is currently working toward the PhD Degree at the Structure des Interfaces et Fonctionnalité des Couches Minces (SIFCOM) laboratory. His research is focused on the fabrication and studies of Nd-doped materials for laser applications.

Christian Dufour obtained his PhD in 1993 and is currently Professor in Physics (condensed matter) at the University of Caen. He developed a model of ion-matter interaction since 2000', he has then focused his research in the fields of photonics, particularly in the modelling of luminescence properties and optical gain in rare-earth ions and silicon nanograins co-doped silica. $\mathrm{He}$ is involved now in electronic structure calculations via the DFT approach in order to explain the role of the $\mathrm{Si}$ grain size, the $\mathrm{Si}_{-} \mathrm{SiO}_{2}$ interface and the rare earth environment on the luminescence properties.

Richard Rizk received the Doctorat d'Etat Degree in Physics from the University of Paris, France, in 1976. He is currently the Director of Research at the Centre National de la Recherche Scientifique (CNRS) and Heads the Structure des Interfaces et Fonctionnalité des Couches Minces (SIFCOM) laboratory. His current research interests include solid-state physics covering the fields of electronic, optoelectronic and photonic Si-based materials and devices. He is the author or co-author of more than 130 papers, the author of several invited papers and contributions to special issues and books, the Editor of conference proceedings, and the holder of one patent.

\section{Introduction}

Since the discovery of efficient visible photoluminescence (PL) at room temperature from porous silicon [1], numerous studies dealing with silicon nanostructures have been carried out. Such emission properties offer promising development for Si-based photonics that are increasingly needed to meet the urgent demand for a high rate communication. Additionally, Si-based integrated photonic devices can also enable the mixing within the same chip of both microelectronic and photonic functions.

$\mathrm{Si}$ nanoclusters ( $\mathrm{Si}-\mathrm{nc}$ ) embedded in a $\mathrm{SiO}_{2}$ insulating matrix in single layer [2-7] or multilayer [8-12] systems present a much better chemical and mechanical stability than other nanoscaled $\mathrm{Si}$ structure porous silicon. The visible emission observed in these systems consists of a broad band emission peaking between $700 \mathrm{~nm}$ and $950 \mathrm{~nm}$, attributed to the quantum confinement of carriers in the nanoscaled Si [13]. To reach a better control of the emission direction and to improve the efficiency of the 
Si-nc photoluminescence, the Si-based active layers have been used as active layers in an optical microcavity [14-16].

Apart from the emission properties of Si-nc, such nanostructures offer a strong interest in the optical communication field at $1.54 \mu \mathrm{m}$ since they play the role of efficient sensitisers of the neighbouring $\mathrm{Er}^{3+}$ ions when Si-nc and the rare earth ions are embedded in an insulating matrix. This results in a 3-4 order of magnitude increase of the $\mathrm{Er}^{3+}$ effective absorption excitation cross section from about $10^{-20} \mathrm{~cm}^{2}$ for Er-doped silica $[17,18]$ to $10^{-16} \mathrm{~cm}^{2}$ for silica do-doped with $\mathrm{Er}$ and Si-nc [19]. Such a value for the effective absorption cross section, $\sigma_{\text {abs }}^{\text {eff }}$, is close to that of the absorption cross section $\sigma_{\text {abssi }}$ of the Si-nc $[20,21]$. This demonstrates that $\mathrm{Er}^{3+}$ ions are excited through the Si-nc as evidenced by many studies devoted to this domain during the last decade [22-26]. Such nanocomposite materials present a great potential for producing optical gain because of:

- the excitation of Er ions through the Si-nc that benefits from the high absorption cross section of Si-nc for optical pumping in the visible

- the advantage offered by the excitation via the Si-nc that allow a broad spectral absorption band

- the increase of the active layer refractive index due to the presence of Si-nc with respect to that of silica leading to a possible good confinement of light.

Moreover, encouraging results on the electroluminescence in such systems [27] together with the achievement of an gain in $\mathrm{Er}$ doped $\mathrm{Si}_{-} \mathrm{SiO}_{2}$ waveguides $[28,29]$ open the possibilities of electrically excited amplifiers. Nevertheless, some detrimental processes such as cooperative up-conversion depending on the Er content, Auger non-radiative de-excitations and confined carrier absorption within Si-nc depending on the pumping fluxes can limit the achievement of a net gain. Such issues fear the debate on the energy transfer mechanism from Si-nc to $\mathrm{Er}^{3+}$ [30] and point out the necessary optimisation of the material in terms of Si-nc density, number of excited $\mathrm{Er}^{3+}$ ions, etc.

Another possible application for the use of Si-nc as sensitisers of other rare earth (RE) elements has been demonstrated recently for $\mathrm{Nd}^{3+}$ ions [31-33]. This $\mathrm{RE}$ ion presents an interesting emission in the near infrared region and is widely used for laser application. The most commonly used transition is around $1.06 \mu \mathrm{m}\left({ }^{4} \mathrm{~F}_{3 / 2} \rightarrow{ }^{4} \mathrm{I}_{11 / 2}\right)$ because of the high gain obtained at this wavelength. Nevertheless, the ${ }^{4} \mathrm{~F}_{3 / 2} \rightarrow{ }^{4} \mathrm{I}_{9 / 2}$ transition can also be used for an emission at around $0.9 \mu \mathrm{m}$. As for the case of Er, the development of $\mathrm{Nd}$ doped $\mathrm{SiO}_{2}$ for integrated devices is limited by the low cross section of its direct excitation [34]. Thus the indirect excitation via the Si-nc offers an increase of the excitation cross section and a broad pumping band. Such advantages pave the way to the fabrication of Nd-doped materials for optically and/or electrically pumped devices compatible with the CMOS technology.

In this paper, we report on the fabrication process and the photoluminescent properties of Si-based nanostructures doped or undoped with $\mathrm{Er}^{3+}$ or $\mathrm{Nd}^{3+}$ ions. The reactive magnetron sputtering process allows the deposition of $\mathrm{Si}$-rich $\mathrm{SiO}_{2}$ single layer (SRSO) or $\mathrm{SRSO} / \mathrm{SiO}_{2}$ multilayers in which the $\mathrm{RE}$ ions can be incorporated. The effect of the microstructure on the sensitising efficiency of Si-nc towards the $\mathrm{RE}$ elements is studied. A preliminary study of an optical planar $\mathrm{Si} / \mathrm{SiO}_{2}$ microcavity is also reported. 


\section{Experimental}

The layers and multilayers (MLs) used for this study were deposited by reactive magnetron sputtering which consists in the sputtering of a pure silica target topped or not with RE oxide chips by a plasma containing a mixture of hydrogen and argon. This process benefits from the ability of the hydrogen species, formed in the plasma, to reduce the oxygen originating from the pure silica target allowing the growth of the so-called Si-rich silicon oxide (SRSO) layer.

The RE doped layers have been obtained by the sputtering of a $\mathrm{SiO}_{2}$ target topped with RE chips under different hydrogen rates, $r_{H}\left(r_{H}=P_{H_{2}} / P_{H_{2}}+P_{A r}\right)$ in the plasma. $r_{H}$ allows the control of the $\mathrm{Si}$ excess incorporated in the film, while the number of RE chips placed on top of the $\mathrm{SiO}_{2}$ target enables the adjustment of the $\mathrm{RE}$ content. The films were deposited on non-intentionally heated Si substrate with a power density of $0.75 \mathrm{~W} . \mathrm{cm}^{-2}$, before being annealed during one hour under a $\mathrm{N}_{2}$ flux at different temperatures $T_{a}$ ranging from $700^{\circ} \mathrm{C}$ to $1100^{\circ} \mathrm{C}$.

The maximisation of the RE emission requires the determination of some critical parameters governing the efficiency of the energy transfer between the Si-nc and the $\mathrm{RE}$ ions. For this purpose, we have developed for Er ions a multilayer approach consisting in the alternative deposition of SRSO and silicon oxide (SO) layers in which the Er ions can be incorporated either in SRSO or SO sublayers. The first configuration, SRSO-Er/SO MLs called ML-A (Figure 1(a)), was obtained by depositing alternatively, on a $\mathrm{Si}$ substrate heated at $650^{\circ} \mathrm{C}$, a SRSO-Er sublayer provided by the sputtering of a $\mathrm{SiO}_{2}$ target topped with a given number of $\mathrm{Er}_{2} \mathrm{O}_{3}$ pellets under a plasma containing $50 \%$ of $\mathrm{H}_{2}\left(r_{H}=50 \%\right)$ and a SO sublayer obtained by the sputtering of a bare $\mathrm{SiO}_{2}$ target under a pure argon plasma $\left(r_{H}=0 \%\right)$. The second configuration, SRSO/SO-Er MLS, called ML-B (Figure 1(b)), was fabricated by inverting the gas procedure on the previously described targets. On the basis of the results obtained in the case of Er-doped SRSO layers, the MLs were annealed at $900^{\circ} \mathrm{C}$ during one hour. More details concerning the fabrication process can be found elsewhere [35].

Figure 1 Schematic of the Si-rich silicon oxide (SRSO/Silicon oxide (SO) multilayer (ML) configurations for the two localisations of Er dopant: either within SRSO (ML-A) or within the SO sublayers (ML-B). The amorphous or crystallised Si nanoclusters are represented by circles and the Er ions by the dots: (a) ML-A configuration and (b) ML-B configuration

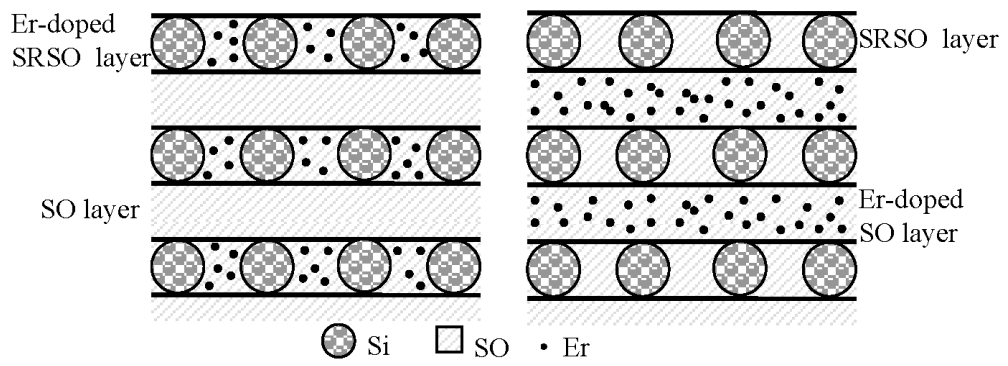

(a)

(b) 
For the microcavity whose active layer is RE-free $\mathrm{SRSO} / \mathrm{SiO}_{2}$ multilayers, the growth of the $\mathrm{SiO}_{2}$ layer is obtained upon interrupting the hydrogen flux in the plasma. The multilayers have been deposited at $600^{\circ} \mathrm{C}$ with an hydrogen rate, $r_{H}$, of $70 \%$. The active layer is constituted of $21 \mathrm{SRSO} / \mathrm{SiO}_{2}$ periods $(3 \mathrm{~nm} / 10 \mathrm{~nm})$ and has a refractive index of 1.6 at $633 \mathrm{~nm}$. The Bragg mirrors consist of three periods of $\mathrm{SRSO} / \mathrm{SiO}_{2}$ having the following characteristic: SRSO thickness $t_{S R}=59 \mathrm{~nm}, n=3.5$ and silica thickness $t_{S O}=141 \mathrm{~nm}, n=1.46$. For the comparison, a multilayer constituted of the same number of periods has been used as a reference. The samples have been annealed at $1100^{\circ} \mathrm{C}$ during one hour to allow the phase separation between $\mathrm{Si}$ and $\mathrm{SiO}_{2}$ and also to recover the non-radiative defects.

The structural analyses have been performed by means of conventional (JEOL 2010) and high resolution (TOPCON 002B) transmission electron microscopes (CTEM, HREM) on samples prepared in the cross section configuration, while the optical properties were analysed by room temperature photoluminescence (PL) measurements. For RE doped layers, the PL experiments have been performed using the $488 \mathrm{~nm}$ or $476.5 \mathrm{~nm}$ argon laser lines that may be resonant or non-resonant depending on the considered rare earth ( $\mathrm{Er}$ or $\mathrm{Nd}$ ). The luminescence detection is obtained through a $\mathrm{Ge}$ detector. The emission lifetime measurements have been carried out with a laser beam chopped at a frequency of $15 \mathrm{~Hz}$ and a low pumping power of about $3 \mathrm{~mW} \cdot \mathrm{cm}^{-2}$. The overall response time of the system is lower than $0.5 \mathrm{~ms}$. Concerning the optical characteristics of the microcavity, a $488 \mathrm{~nm}$ Ar laser line and a pulsed YAG laser tuned to the blue absorption of the silicon nanocrystals were used. The emitted light has been collected by a photomultiplier through a $1 \mathrm{~m}$ single monochromator. The Si lifetime has been recorded with a fast digital oscilloscope triggered by the laser for low energy pumping power. The spatial resolution of the PL emission has been investigated using an optical fibre of $600 \mu \mathrm{m}$ in diameter mounted on a rotating stage giving rise to a collecting angle below $1^{\circ}$.

\section{Results and discussion}

\subsection{Er-doped SRSO films}

The effect of the hydrogen rate $r_{H}$ on the Er emission is displayed on Figure 2. The PL spectra have been recorded under the non-resonant $476.5 \mathrm{~nm}$ laser line, in order to ensure that the Er ions are only excited through the Si-nc. The inset compares the spectra obtained under a resonant $488 \mathrm{~nm}$ excitation line for the layer free from Si-nc $\left(r_{H}=0 \%\right)$ and for that containing Si-nc. For this latter, one can notice the enhancement by a factor 250 of the Er emission in comparison with that free from Si-nc. This demonstrates the efficient sensitising of the Si-nc towards the Er ions. This is confirmed by the absence of the Er emission when the sample free from $\mathrm{Si}$ excess $\left(r_{H}=0 \%\right)$ is excited through the non-resonant line. The evolution of the PL emission with $r_{H}$ indicates that the incorporation of hydrogen in the plasma favours the coupling rate between the Si-nc and the surrounding Er ions. Considering the previously reported SIMS and RBS results that reveal Er and Si contents almost independent on $r_{H}$ and equal of about $5 \times 10^{19}$ at.cm $^{-3}$ and 11 at.\%, respectively [36], such PL behaviour can be explained by an increase of the number of Si-nc coupled to the Er ions. This increase of the Si-nc density is confirmed by HREM micrographs for which one can observe numerous $\mathrm{Si}$ nanocrystals having 
an average size of $3 \mathrm{~nm}$ for the sample fabricated with the lowest hydrogen rate (Figure 3(a)), whereas few Si nanocrystals with an average size of $2 \mathrm{~nm}$ have been scarcely detectable for the highest $r_{H}$ deposited layer (Figure 3(b)). Such an observation suggests that the increase of the hydrogen rate in the plasma would induce some multiplication of the Si nucleation sites which, in turn, limits the size of the growing Si-nc. This can be attributed to the increasingly strong interaction between the reactive $\mathrm{H}$-based species in the plasma with the growing surface, when is $r_{H}$ increased. Apart from the sensitising role of the Si-nc towards the Er ions which enhances the Er PL emission by a factor 250 , the effect of the Si-nc density has been clearly evidenced regardless of its crystalline or amorphous nature. These results demonstrate that

- amorphous Si-nc are also efficient sensitisers of Er ions

- the coupling rate between $\mathrm{Er}$ and $\mathrm{Si}-\mathrm{nc}$ is greatly favoured by the increase of the Si-nc density for a given Er content.

Figure 2 Photoluminescence spectra obtained in the range of Er emission using a non-resonant $476.5 \mathrm{~nm}$ excitation line for the indicated values of hydrogen rate $r_{H}$. The inset compares the photoluminescence spectra recorded on Si-free sample $\left(r_{H}=0 \%\right)$ and on typical Si-rich sample $\left(r_{H}=50 \%\right)$

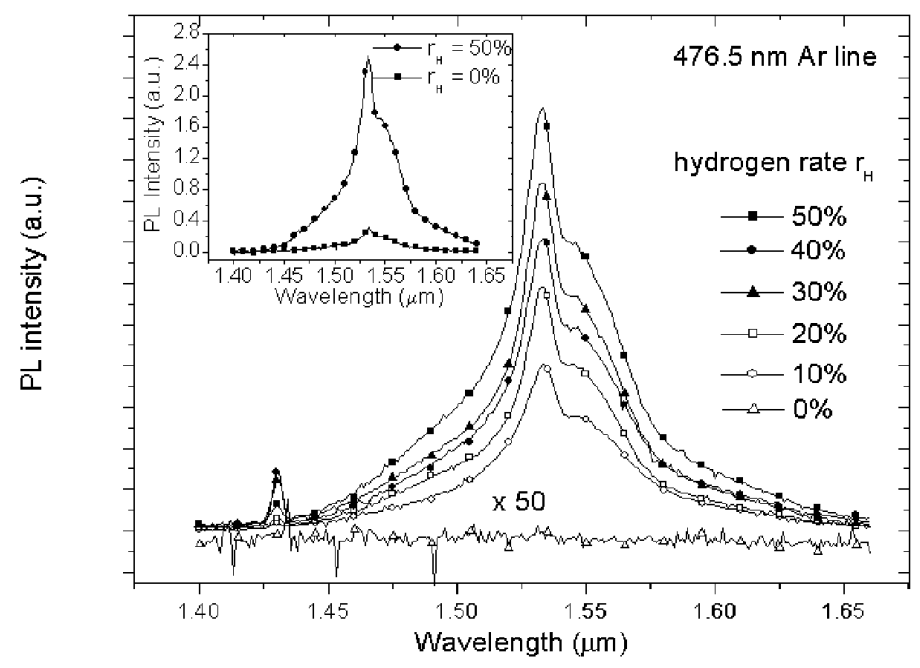

Figure 3 High resolution electron micrographies of the films deposited with (a) $r_{H}=10 \%$ and (b) $r_{H}=50 \%$
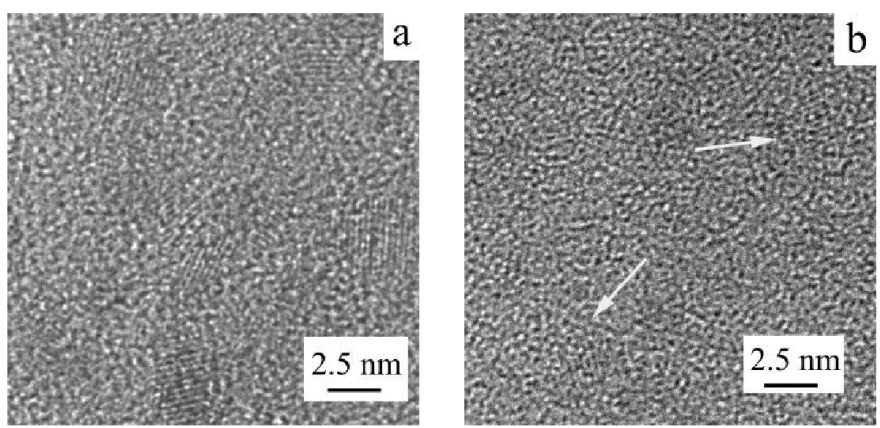
In addition to the already described effect of $r_{H}$, the Si-nc density can also be monitored by the annealing temperature $T_{a}$. Figure 4 reports a typical comparison of the PL spectra recorded on the layers fabricated with $r_{H}=50 \%$ and annealed at different temperatures ranging from $700^{\circ} \mathrm{C}$ to $1100^{\circ} \mathrm{C}$. The emission peak at $1.54 \mu \mathrm{m}$ was found maximum for the sample annealed at $900^{\circ} \mathrm{C}$. It is also the case for the samples obtained with different $r_{H}$ values as typically shown in the inset. It is worth noticing that the Si-nc formed upon annealing at $900^{\circ} \mathrm{C}$ are amorphous since no crystallisation has been observed by HREM (not shown here). Consequently, one can infer that the sensitising action of amorphous Si-nc is confirmed [24,37] and that an optimum Si-nc density is obtained at $900^{\circ} \mathrm{C}$. One can, however, argue that the PL decrease for $T_{a}>900^{\circ} \mathrm{C}$ can be explained by some detrimental effect such as defect generation or the optically active $\mathrm{Er}^{3+}$ dissociation induced by the annealing treatment. To shed light on these aspects, the lifetime of emission $\tau_{e m}^{E r}$ has been systematically measured with $T_{a}$. The results show a systematic increase from $3 \mathrm{~ms}$ for the samples annealed at $700^{\circ} \mathrm{C}$ to $7 \mathrm{~ms}$ for those annealed at $1100^{\circ} \mathrm{C}$. Since $\tau_{e m}^{E r}$ includes both radiative and non-radiative decays, this improvement with $T_{a}$ reflects the recovery of the non-radiative centres. Consequently, the defect generation or the optically active $\mathrm{Er}^{3+}$ dissociation cannot be responsible of the PL decrease observed for $T_{a}>900^{\circ} \mathrm{C}$. One can also remark that the effective absorption cross section values show a monotonic behaviour towards $T_{a}$ (as well as towards $r_{H}$ ) and appear comparable to the absorption cross section of the Si nanograins [38,39] with an average value of about $5 \times 10^{-16} \mathrm{~cm}^{2}$. This provides additional support and evidence to the indirect excitation of Er ions through the Si-nc. The PL evolution with Ta can be explained by an optimal compromise between the presence of a high quantity of non-radiative defects for the lowest temperatures $\left(T_{a}<900^{\circ} \mathrm{C}\right)$ and a low density of large Si-nc inside the matrix for the highest ones $\left(T_{a}>900^{\circ} \mathrm{C}\right)$. Thus for this latter case, apart from the lower density of Si-nc which influences the coupling rate with Er, there might be an issue relating to meet Si-nc which can exceed the critical value for quantum confinement. These considerations point out the importance of some key parameters governing the optimisation of the material such as the optimum Si-nc size and the critical value of its spacing from the Er ions for an efficient energy transfer. These two critical parameters will be carefully examined below through the multilayers approach. On the basis of these promising results, rib-loaded waveguides have been fabricated with such composite structure to look for an optical gain at $1535 \mathrm{~nm}$. The measurements performed on these waveguides have evidenced that the presence of Si-nc strongly improves the efficiency of $\mathrm{Er}^{3+}$ excitation, as expected according to the above described results. However, these Si-nc are also responsible of detrimental effects such as confined carrier absorption or Mie scattering that limit the achievement of a net gain by introducing optical losses $[29,40]$. The authors have succeeded to decrease theses losses by lowering the annealing time and controlling the refractive index of the layers [41]. Such a device has to be optimised through, among others, an increase of the number of excited Er ions [42]. Moreover, the mechanisms governing for example, the energy transfer process, have to be deeply understood to succeed in the fabrication of planar waveguides having net gain at $1.54 \mu \mathrm{m}$. 
Figure 4 Photoluminescence spectra recorded with a non-resonant excitation line (476.5 nm) on the samples grown with $r_{H}=50 \%$ and annealed at the indicated temperature.

The inset show the variation of the photoluminescence intensity at $1.54 \mu \mathrm{m}$ obtained with a non-resonant excitation line $(476.5 \mathrm{~nm})$ for some values of $r_{H}$ in function of the annealing temperature

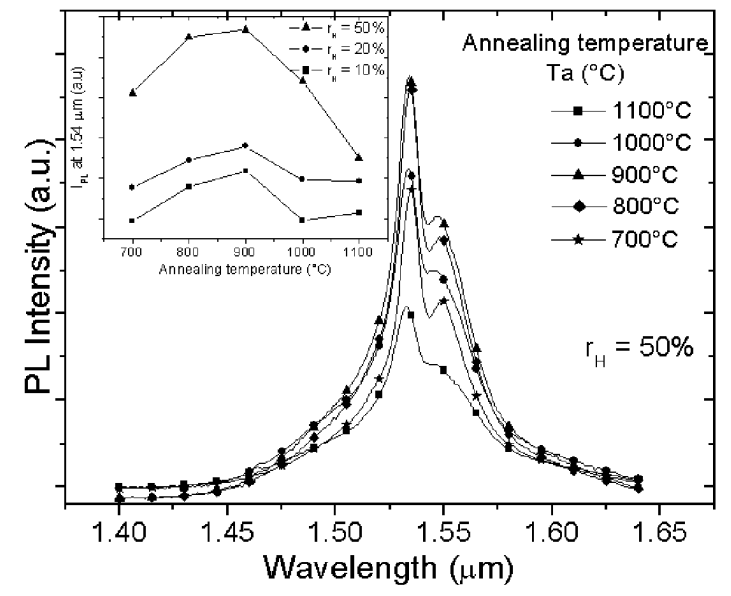

\subsection{Er-doped (SRSO/SO) multilayers}

The above described results have pointed out the necessity to optimise the coupling rate between Si-nc and Er ions through different ways. Different recent works give some insight on the knowledge of some critical parameters governing the transfer. For example, some authors have studied the influence of the photon excitation flux and the number of excitable Er per Si-nc [43], the impact of the dynamics of the energy transfer (ET) from Si-nc to Er [44,45]. Some trend of an increasing ET efficiency for decreasing the Si grain size $\left(d_{S i}\right)[46,47]$, together with the studies on the characteristic carrier-Er interaction distance $\left(d_{\text {int }}\right)[48,49]$ have been pointed out. The determination of the two parameters, $d_{S i}$ and $d_{\text {int }}$, allows the optimisation of the material in terms of sensitisers (Si-nc) and emitting centre (Er) concentrations, and requires, therefore, an exact determination for the realisation of high performance active device.

\subsubsection{Effect of the Si-nc size}

The effect of the Si-nc size on the emission of Er has been studied using the MLs in the configuration ML-A for different values of the Er-doped SRSO thickness, $t_{S R}$ in the $1.2-7.5 \mathrm{~nm}$ range. Figure 5 shows some typical HREM image of the MLs for $t_{S R}=1.8$, 3.8 and $5 \mathrm{~nm}$. A careful observation of these micrographs reveals the presence of Si nanocrystals within the SRSO sublayers for $t_{S R} \geq 3.8 \mathrm{~nm}\left(t_{S R}=3.8 \mathrm{~nm}\right.$ and $5.0 \mathrm{~nm}$, Figure 5(b) and (c)) whereas no crystallisation can be observed in the thinner SRSO sublayers $\left(t_{S R}=1.8 \mathrm{~nm}\right.$ Figure 5(a)). The amorphous state for thin SRSO sublayers has been already noticed.

For such low thickness values, the crystallisation would require an annealing temperature higher than that used here $\left(900^{\circ} \mathrm{C}\right)$ [50]. These amorphous Si-nc are, however, playing their role of sensitisers as described above and confirmed below. Figure 6 shows the variation of the Er PL intensity against $t_{S R}$. The PL intensity increases 
gradually by about $20 \%$ when $t_{S R}$, i.e., $d_{S i}$, increases from $1.2 \mathrm{~nm}$ to $3.8 \mathrm{~nm}$, and then decreases abruptly for $t_{S R}$ higher than $4 \mathrm{~nm}$. For larger Si-nc, a smooth lowering of the PL intensity is noticed. This drop of the emission for larger Si-nc represents a clear evidence of some size effect when $t_{S R}$ reaches $4 \mathrm{~nm}$ and suggest that $\mathrm{Si}-\mathrm{nc}$ becomes ineffective to sensitise the Er ions. Such behaviour can be attributed to the weak carrier confinement in large Si-nc whose size is comparable or larger that the exciton Bohr radius and to a concomitant shrinkage of the band gap preventing any resonance with the upper level of Er. The existence of an emission for the larger Si-nc grains $\left(t_{S R}=7.5 \mathrm{~nm}\right)$ attests of the presence of small Si-nc with a size smaller than $t_{S R}$. Another origin of such a drop is the occurrence of deexcitation processes such as energy back transfer and Auger-type interaction between Er and carriers. However the small changes in the PL intensity and Er lifetime with the temperature experiments (not shown here) exclude the existence of such deexcitation process responsible of the temperature quenching noticed in $\mathrm{c}-\mathrm{Si}$ $[51,52]$.

Figure 5 High resolution electron microscopy micrographies of the Si-rich silicon oxide (SRSO)/silicon oxide (SO) multilayers for the three values of the SRSO thickness $t_{S R}$ : (a) $t_{S R}=1.8 \mathrm{~nm}$; (b) $t_{S R}=3.8 \mathrm{~nm}$ and (c) $t_{S R}=5 \mathrm{~nm}$
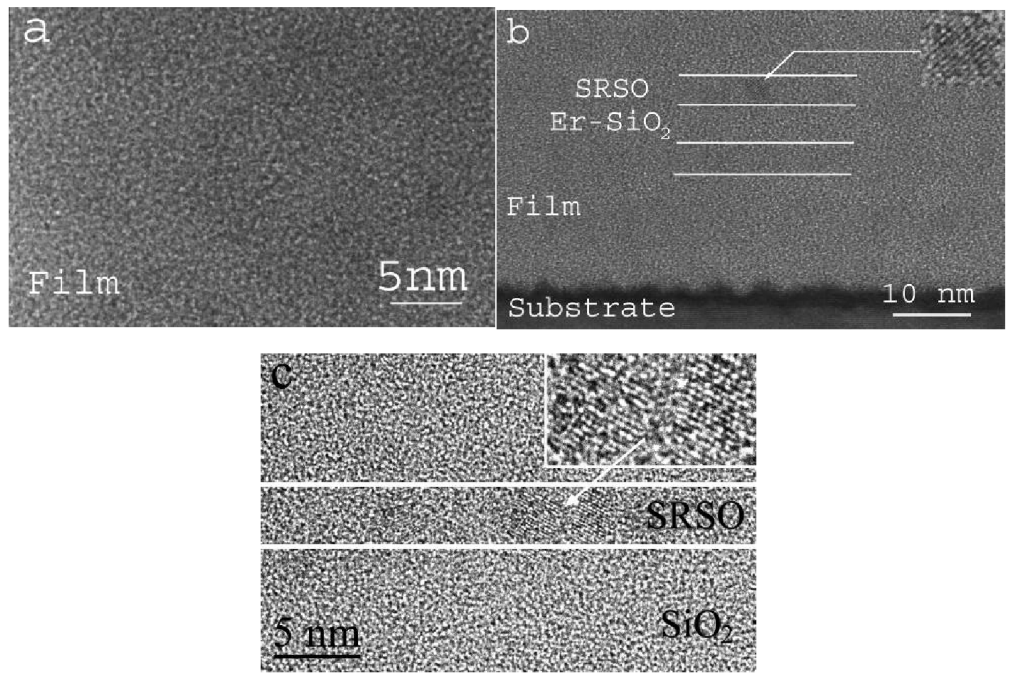

Figure 6 Evolution of the photoluminescence intensity at $1.54 \mu \mathrm{m}$ against $t_{S R}$ for the Er-doped $\mathrm{SRSO} / \mathrm{SO}$ multilayers (configuration ML-A)

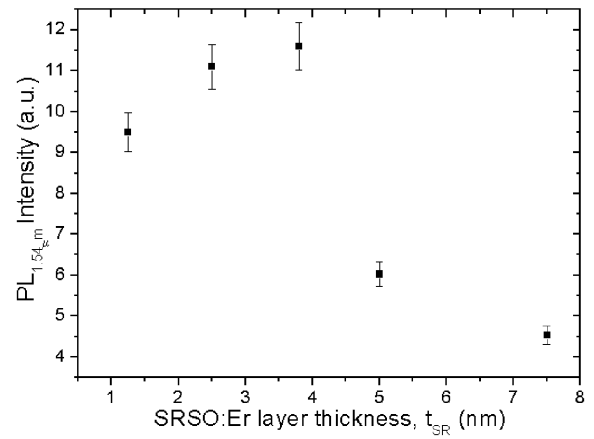




\subsubsection{Critical carrier-Er interaction distance}

The critical interaction distance has been determined by analysing the optical properties of the MLs in ML-B configuration when the Er-SO sublayer thickness $\left(t_{S O}\right)$ is varied from $2 \mathrm{~nm}$ to $30 \mathrm{~nm}$ for three typical values of $t_{S R}(1.8,3.8$ and $5.0 \mathrm{~nm})$. Figure 7 displays the typical evolutions of the PL intensity $\left(I_{P L}\right)$ at $1.54 \mu \mathrm{m}$ against $t_{S O}$. A similar behaviour can be noticed for the three curves which consists first in an increase of $I_{P L}$ due to an increase of the number of excited ions and followed by the saturation of $I_{P L}$ that can be explained by the presence of Er ions in the central region of SO sublayers that are out from the energy transfer range. The different trends for reaching the saturation suggests that the Er distance from amorphous Si-nc formed in thin SRSO sublayers is much narrower than that from crystallised Si-nc in thicker SRSO sublayers. Concerning the thicker SRSO sublayers, and according to the results described above, large Si-nc become inefficient sensitisers. Thus this effect coupled with the probable presence of smaller Si-nc since the PL does not vanish, can explain the evolution of $I_{P L}$ for $t_{S R}=5 \mathrm{~nm}$ and will interfere in the determination of the $d_{\text {int. }}$. For this case, one can only expect a confirmation of a trend deduced for the two smaller $t_{S R}$. To be sure that the evolutions displayed on Figure 7 are not the consequence of a difference in the quality of the layers, we have examined the lifetime $\tau_{e m}^{E r}$ for the various structures with different $t_{S O}$ values (Figure 8). The plots attest of the equal quality of the layers with a value of $\tau_{e m}^{E r}$ which remains confined between $3.3 \mathrm{~ms}$ and $5.7 \mathrm{~ms}$ without any clear trend towards $t_{S R}$ or against $t_{S O}$.

To determine the characteristic interaction distance, the experimental data have been reproduced by two different approaches, one dealing with an exchange interaction, the other with a dipole-dipole interaction described by an $\exp \left(-x / x_{0}\right)$ or $x^{-6}$ law, respectively [53,54]. $x$ is the distance between $\mathrm{Er}$ and $\mathrm{Si}$-nc and $x_{0}$ represents the characteristic Er-Si-nc distance. For the three values of $t_{S R}$, the best fits were obtained with the same function of exchange interaction as shown in Figure 8. The simulations plot were performed with the following values of $x_{0}: 0.8 \mathrm{~nm}$ for $t_{S R}=1.8 \mathrm{~nm}, 5.2 \mathrm{~nm}$ for $t_{S R}=3.8 \mathrm{~nm}$ and around $10 \mathrm{~nm}$ for $t_{S R}=5 \mathrm{~nm}$. Considering that the Er ions are excited from the two adjacent SRSO sublayers, the reported values are twice of the critical interaction distance $d_{\text {int. }}$. Consequently, $d_{\text {int }}$ is about $0.4 \pm 0.1 \mathrm{~nm}$ for $t_{S R}=1.8 \mathrm{~nm}$, $\sim 2.6 \pm 0.4 \mathrm{~nm}$ for $t_{S R}=3.8 \mathrm{~nm}$, and $\sim 5.0 \pm 1 \mathrm{~nm}$ for $t_{S R}=5.0 \mathrm{~nm}$. As expected above, the simulation of the data obtained for $t_{S R}=5.0 \mathrm{~nm}$ is not as good as for the two other $t_{S R}$ values since different effects are combining themselves in the recorded optical properties and lead to some difficulty to separate the unique effect of $d_{\text {int }}$. On the basis of the HREM observation (Figure 5), the interaction distance seems to be dependent on the amorphous or crystalline state of the Si-nc as reported earlier if we compare the work of Jhe et al. [47] with that of Kimura et al. [48] who have obtained closer values to ours with $0.5 \pm 0.1 \mathrm{~nm}$ and $2-3 \mathrm{~nm}$, respectively. Such discrepancies can be therefore attributed to the nature of our Si-nc. 
Figure 7 Evolution of the experimental data of the PL intensity at $1.54-\mu \mathrm{m}$ in function of the thickness of Er-doped silicon oxide (SO) layer of the multilayers ML-B, for three typical values of SRSO thickness $t_{S R}$ : (a) $1.8 \mathrm{~nm}$; (b) $3.8 \mathrm{~nm}$ and (c) $5.0 \mathrm{~nm}$. Comparison of the experimental (symbols) and simulated (lines) evolutions of the PL intensity at $1.54-\mu \mathrm{m}$ in function of the Er-doped silicon oxide (SO) layer thickness. The simulated plots are the results of fits using an exchange interaction mechanism decreasing as $\exp \left(-x / x_{0}\right)$

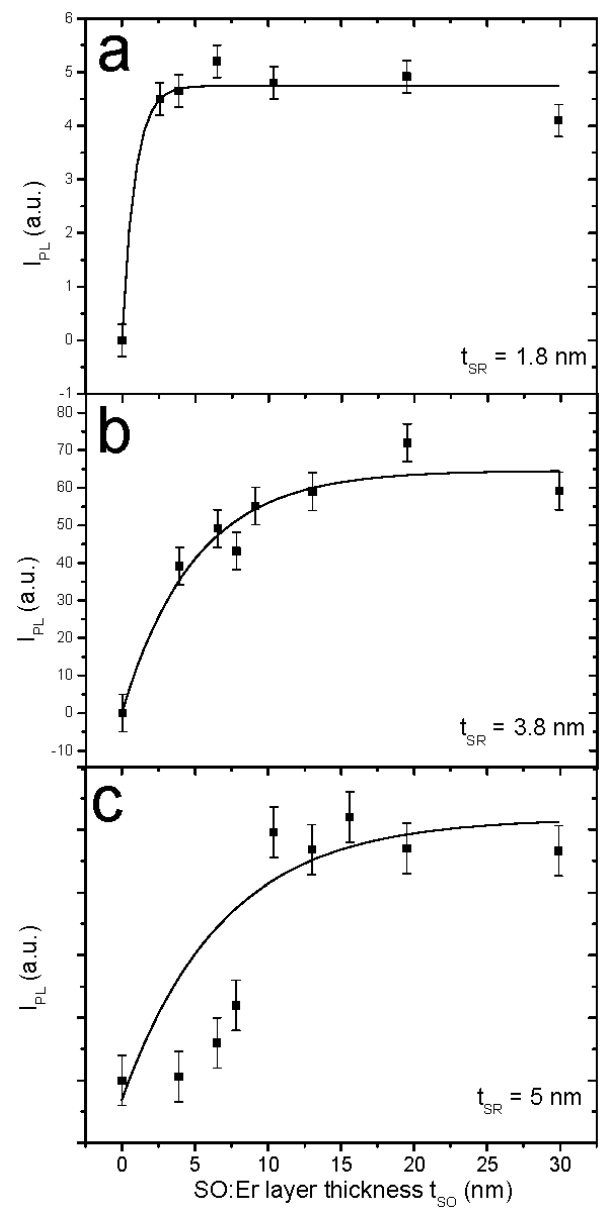

In this connection, one can expect an influence of the phase nature of Si-nc on the carrier-Er interaction through both carrier localisation and interface quality. In the case of the amorphous sensitisers, the probability that the carriers are trapped at the interface is high whereas in the case of crystallised Si-nc, these carriers would be free within the nanocrystal. Thus the carrier wavefunction would be localised at the interface for the amorphous case with some overlapping with that of Er ions. In such case, $d_{\text {int }}$ represents the distance separating the Er ion from the interface of the sensitisers. When the Si-nc size increases, nanocrystallites are formed and in this case we have to take into account the size of the grain in the value of $d_{\text {int }}$. 
Figure 8 Evolution of the Er emission lifetime in function of the Er-doped silicon oxide thickness $\left(t_{S O}\right)$ for the indicated values of the Si-rich silicon oxide layer thickness $t_{S R}$

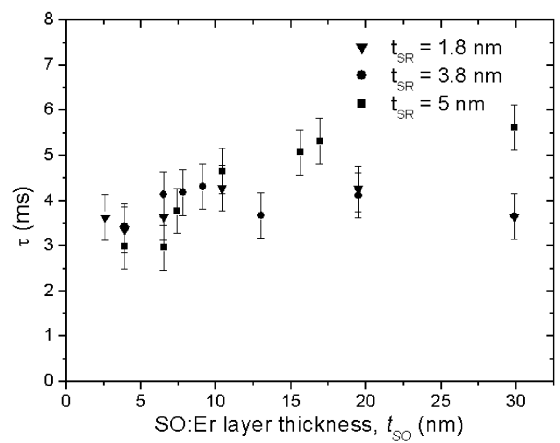

\section{$3.3 \quad$ Nd-doped SRSO films}

By replacing the $\mathrm{Er}_{2} \mathrm{O}_{3}$ chips with $\mathrm{Nd}_{2} \mathrm{O}_{3}$ chips on the $\mathrm{SiO}_{2}$ target, Nd-doped SRSO thin films have been fabricated using the same reactive process. Figure 9 reports the PL spectra recorded with the $488 \mathrm{~nm}$ Ar line excitation for layers prepared in the plasma with different hydrogen partial pressures $\left(P_{H_{2}}\right)$. The absorption spectrum of a thick $\mathrm{Nd}$-doped $\mathrm{SiO}_{2}$ sputtered layer displayed in the inset of Figure 9 evidences that the $488 \mathrm{~nm}$ excitation is almost non-resonant for the $\mathrm{Nd}^{3+}$ ions in $\mathrm{SiO}_{2}$ since no absorption occurs in this region. The different spectra show that the PL emission of $\mathrm{Nd}^{3+}$ ions is almost undetectable for the sample free from Si excess $\left(P_{\mathrm{H}_{2}}=0\right)$ whereas for $P_{\mathrm{H}_{2}}>0$ the peaks corresponding to the $\mathrm{Nd}^{3+}$ intra 4 f-transitions appear clearly at around $0.9 \mu \mathrm{m}$ and $1.1 \mu \mathrm{m}$. These peaks are the signature of the sensitising role of the Si-nc towards the $\mathrm{Nd}^{3+}$ ions, similarly to that observed in the case of the $\mathrm{Er}^{3+}$ ions. The increase of the hydrogen content in the plasma leads to the concomitant increase of the $\mathrm{Nd}^{3+} \mathrm{PL}$ emission and can be attributed to an increase of the Si-nc density originating from the multiplication of seeds as previously demonstrated for samples doped with Er ions [36].

Figure 9 Room temperature PL spectra of Nd-doped samples fabricated with different hydrogen partial pressures. The inset shows the absorption spectrum of $\mathrm{Nd}^{3+}$ ions in a Nd-doped- $\mathrm{SiO}_{2}$ thick film

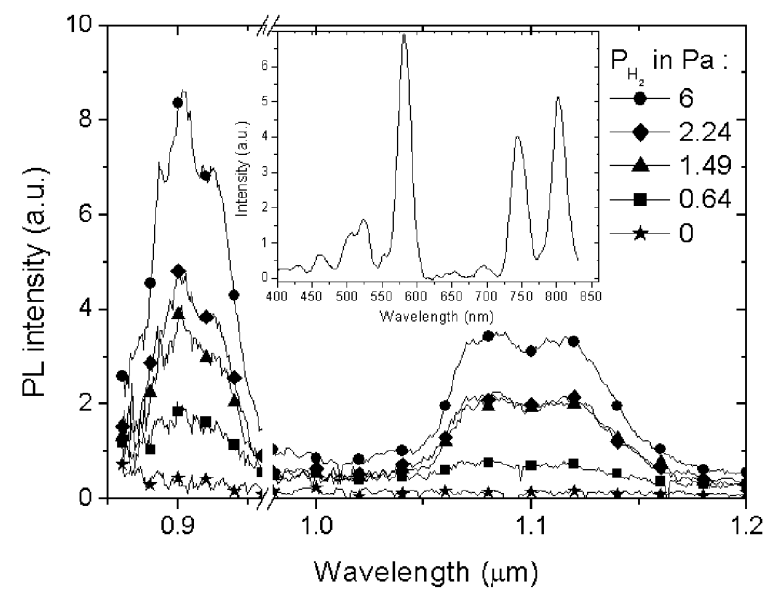


Such an increase of the Si-nc density, i.e., the growth of more numerous smaller Si-nc, favours the numbers of excited $\mathrm{Nd}^{3+}$ ions by reducing the average distance between the sensitiser and the RE, and therefore explain the observed increase of the PL intensity. Figure 10 displays a typical decay curve recorded at $0.9 \mu \mathrm{m}$. The decay exhibits a non-exponential behaviour that has already been observed in silica-based glasses [55]. The experimental curve has been fitted with a double exponential law taking into account a response time of the system of $4 \mu \mathrm{s}$. A lifetime of $47 \mu$ s has been then deduced and is comparable with the value reported for similarly $\mathrm{Nd}^{3+}$ doped silicon rich silicon oxide host [32].

Figure 10 Typical time resolved photoluminescence at $0.9 \mu \mathrm{m}$

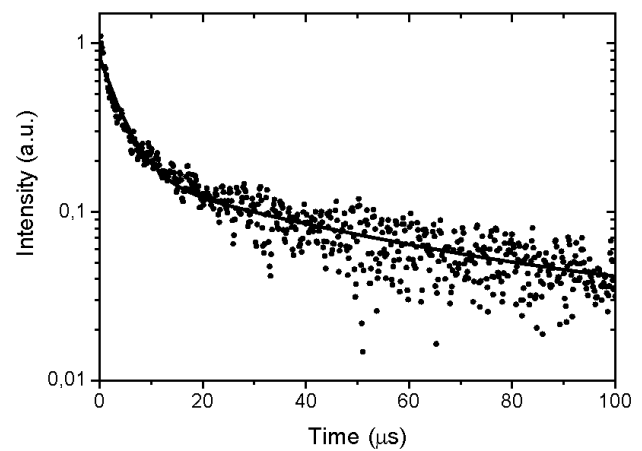

\subsection{Optical planar microcavity}

The emission of layers can be improved in order to be used efficiently in optical devices. Figure 11 exhibits the typical PL spectrum of a $\mathrm{SRSO} / \mathrm{SiO}_{2}$ multilayer recorded at room temperature. It evidences a wide emission band with a FWHM of about $250 \mathrm{~nm}$ and a maximum peaking at about $830 \mathrm{~nm}$. By inserting such a structure into an appropriate Distributed Bragg Reflectors (DBRs) (Figure 12), the emission band is significantly narrowed $(\mathrm{FWHM}=10 \mathrm{~nm})$ while the intensity is increased by a factor of 7 at the resonant wavelength of the microcavity, i.e., $825 \mathrm{~nm}$ (Figure 11). This feature is attributed to the optical properties of the microcavity, as shown in Figure 11 reporting the reflectivity spectrum recorded at normal incidence. It displays the existence of a resonant peak located at $825 \mathrm{~nm}$ inside a photonic broad band (600-1050 nm) having a reflectivity as high as $99.9 \%$. The width of the cavity mode after fitting the spectrum with a Lorentzian law gives a value of $10.1 \mathrm{~nm}$ which corresponds to a microcavity quality factor $Q$ of $82\left(Q=\lambda_{0} / \Delta \lambda\right)$. Such an enhancement of the emission at the resonant wavelength of the microcavity is due, first, to the electric field intensity inside the microcavity which is higher than in the classical multilayer and, secondly, to the redistribution of the photon density of states which entails the selected wavelength range to be emitted normal to the cavity surface. This last point is demonstrated through the study of the angular distribution of the PL emitted light for both samples (Figure 13), i.e., planar microcavity and multilayer reference film. This latter has a PL emission spatially distributed over $90^{\circ}$, whereas the PL emission from the microresonator is concentrated inside a cone of $21^{\circ}$. Figure 14 displays the non-exponential lifetimes of the microcavity and of the multilayered reference sample. The effect of the microcavity is easily visible with a photoluminescence decay time of $24.3 \mu \mathrm{s}$, faster than that of the 
reference sample which reaches a value of $31.4 \mu$ s. This modification of the spontaneous emission rate can be explained by the presence of dielectric boundaries $\left(\mathrm{Si}-\mathrm{nc} / \mathrm{SiO}_{2}\right)$ that modify the local electric field fluctuations but also changes the local optical density of states.

Figure 11 Reflectivity spectrum of the microcavity and room temperature PL emission spectra of the multilayers (reference) and the optical microcavity

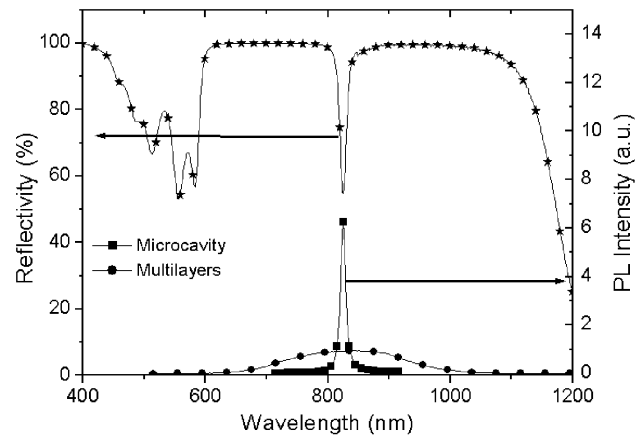

Figure 12 TEM image and schematic representation of the optical planar microcavity
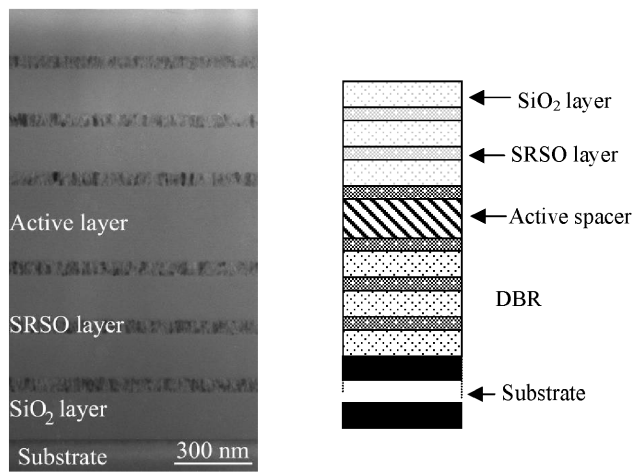

Figure 13 Angular distribution of the PL emission at the resonant wavelength ( $825 \mathrm{~nm}$ ) of the microcavity and the reference multilayers

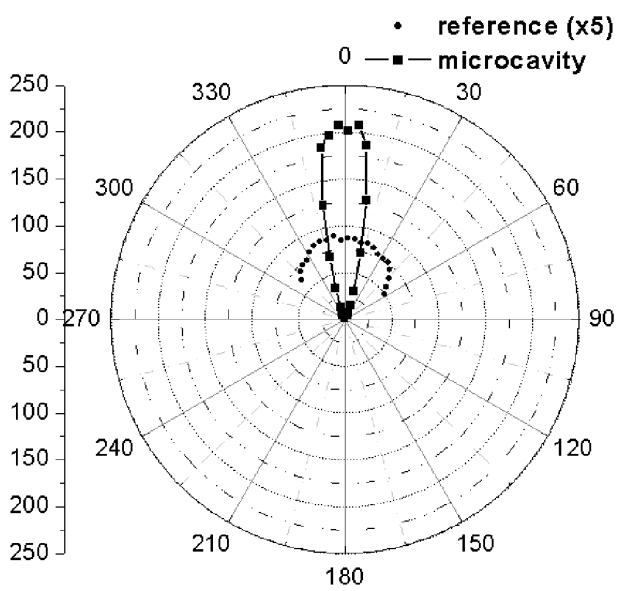


Figure 14 Time resolved photoluminescence at the resonance wavelength of $825 \mathrm{~nm}$ for the reference and the microresonator

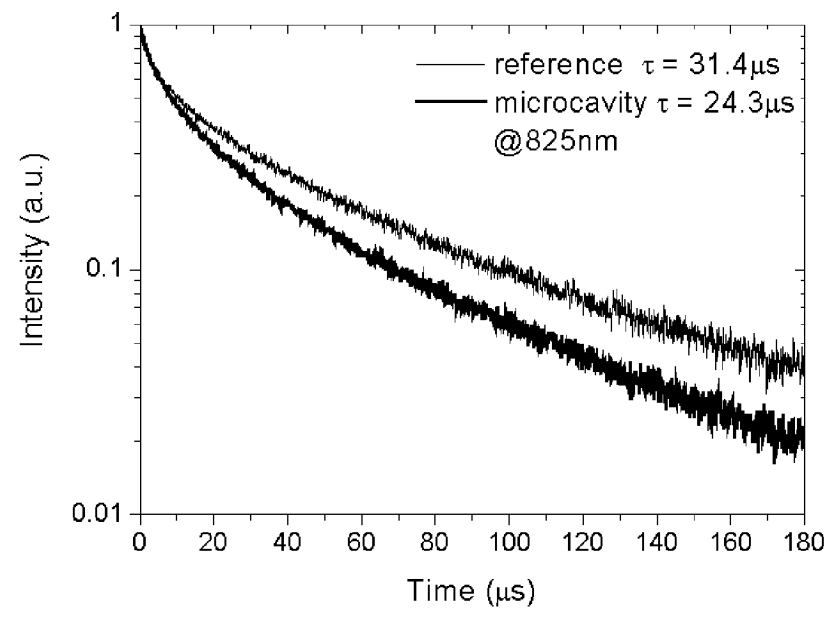

\section{Conclusion}

The different parts of this work show evidence of the active role played by the $\mathrm{Si}$ nanoclusters as sensitisers of the co-dopant rare earth ( $\mathrm{Er}$ and $\mathrm{Nd}$ ) located in their neighbourhood within the silica matrix and as emitters in the case of microcavities. Concerning the Er-doped materials, the efficient sensitising effect of the Si-nc towards the $\mathrm{RE}$ and the determination of the optimum parameters governing the transfer efficiency pave the way for the fabrication of planar waveguides amplifiers at $1.54 \mu \mathrm{m}$ which is the standard communication wavelength. An accurate control of the Si-nc density in the insulating matrix can offer the possibility of an electrical excitation of such devices, which will favour their integration on a Si chip. The sensitising role of the Si-nc has been also demonstrated for the Nd-doped SRSO layers that would offer the possibility of fabricating a Nd laser that operative by electrical excitation. Regarding the microcavities, it is possible to increase the PL intensity and to narrow the emission band of the active layer by inserting it in a distributed Bragg reflector structure. Thus, the quality factor of the microcavity can be improved by increasing the number of Bragg mirrors. Such structure can be fabricated with rare earth doped active layer which will enhance the PL emission of the Er or Nd in a composite SRSO layer.

\section{Acknowledgements}

One of the author (D. Bréard) wishes to acknowledge the Region Basse Normandie and the French CNRS organisation for supporting a part of this work. 


\section{References}

1 Canham, L.T. (1990) 'Silicon quantum wire array fabrication by electrochemical and chemical dissolution of wafers', Appl. Phys. Lett., Vol. 57, No. 10, pp.1046-1048.

2 Inokuma, T., Wakayama, Y., Muramoto, T., Aoki, R., Kurata, Y. and Hasegawa, S. (1998) 'Optical properties of $\mathrm{Si}$ clusters and $\mathrm{Si}$ nanocrystallites in high-temperature annealed $\mathrm{SiO}_{\mathrm{x}}$ films', J. Appl. Phys., Vol. 83, No. 4, pp.2228-2234.

3 Charvet, S., Madelon, R., Gourbilleau, F. and Rizk, R. (1999) 'Ellipsometric spectroscopy study of photoluminescent $\mathrm{Si} / \mathrm{SiO}_{2}$ systems obtained by magnetron co-sputtering', J. Lumin., Vol. 80, pp.257-261.

4 Ledoux, G., Guillois, O., Porterat, D., Reynaud, C., Huisken, F., Kohn, B. and Paillard, V. (2000) 'Photoluminescence properties of silicon nanocrystals as a function of their size', Phys. Rev. B, Vol. 62, No. 23, pp.15942-15951.

5 Botti, S., Coppola, R., Gourbilleau, F. and Rizk, R. (2000) 'Photoluminescence from silicon nano-particles synthesized by laser-induced decomposition of silane', J. Appl. Phys., Vol. 88, No. 6, pp.3396-3401.

6 Iacona, F., Franzò, G. and Spinella, C. (2000) 'Correlation between luminescence and structural properties of Si nanocrystals', J. Appl. Phys., Vol. 87, No. 3, pp.1295-1503.

7 Garrido, B., Lopez, M., Garcia, C., Perez-Rodriguez, A., Morante, J.R., Bonafos, C., Carrada, M. and Claverie, A. (2002) 'Influence of average size and interface passivation on the spectral emission of Si nanocrystals embedded in $\mathrm{SiO}_{2}$, J. Appl. Phys., Vol. 91, No. 2, pp.798-807.

8 Tsybeskov, L., Hirschman, K.D., Dutlagupta, S.P., Zacharias, M., Fauchet, P.M., McCaffrey, J.P. and Lockwood, D.J. (1998) 'Nanocrystalline silicon superlattice produced by controlled recrystallization', Appl. Phys. Lett., Vol. 72, No. 1, pp.43-45.

9 Zacharias, M., Bläsing, J., Veit, P., Tsybeskov, L., Hirschman, K. and Fauchet, P.M. (1999) 'Thermal crystallization of amorphous $\mathrm{Si} / \mathrm{SiO}_{2}$ superlattices', Appl. Phys. Lett., Vol. 74, No. 18, pp.2614-2616.

10 Vinciguerra, V., Franzò, G., Priolo, F., Iacona, F. and Spinella, C. (2000) 'Quantum confinement and recombination dynamics in silicon nanocrystals embedded in $\mathrm{Si} / \mathrm{SiO}_{2}$ superlattices', J. Appl. Phys., Vol. 87, No. 11, pp.8165-8173.

11 Gourbilleau, F., Portier, X., Ternon, C., Voivenel, P., Madelon, R. and Rizk, R. (2001) 'Si-rich/ $\mathrm{SiO}_{2}$ nanostructured multilayers by reactive magnetron sputtering', Appl. Phys. Lett., Vol. 78, No. 20, pp.3058-3060.

12 Ternon, C., Gourbilleau, F., Dufour, C., Madelon, R., Portier, X. and Rizk, R. (2002) 'Emission properties of Si-rich silicon oxide/silica multilayers synthesized by reactive magnetron sputtering', Recent. Res. Dev. Mat. Sci. Eng., Vol. 1, pp.215-234.

13 Cullis, A.G., Canham, L.T. and Calcott, P.D.J. (1997) 'The structural and luminescence properties of porous silicon', J. Appl. Phys., Vol. 82, No. 3, pp.909-965.

14 Lockwood, D.J., Dharma-Wardana, M.W.C., Tit, N. and Sullivan, B.T. (2000) 'Visible light emission from $\mathrm{Si} / \mathrm{SiO}_{2}$ multilayers in planar microcavities', Physica E, Vol. 6, Nos. 1-4, pp.201-204.

15 Iacona, F., Franzò, G., Moreira, E.C., Pacifici, D., Irrera, A. and Priolo, F. (2002) 'Luminescence properties of Si nanocrystals embedded in optical microcavities', Mater. Sci. Eng., C, Vol. 19, Nos. 1-2, pp.377-381.

16 Amans, D., Callard, S., Gagnaire, A., Joseph, J., Huisken, F. and Ledoux, G. (2003) 'Spectral and spatial narrowing of the emission of silicon nanocrystals in a microcavity', J. Appl. Phys., Vol. 95, No. 9, pp.5010-5013.

17 Miniscalco, W.J. (1991) 'Erbium-doped glasses for fiber amplifiers at $1500 \mathrm{~nm}$ ', J. Lightwave Technol., Vol. 9, pp.234-250.

18 Polman, A. (1997) 'Erbium implanted thin films photonic materials', J. Appl. Phys., Vol. 82, No. 1, pp.1-39. 
19 Priolo, F., Franzò, G., Pacifici, D., Vinciguerra, V., Iacona, F. and Irrera, A. (2001) 'Role of the energy transfer in the optical properties of undoped and Er-doped interacting $\mathrm{Si}$ nanocrystals', J. Appl. Phys., Vol. 89, No. 1, pp.264-272.

20 Kovalev, D., Dietmer, J., Heckler, H., Polinski, G., Künzner, N. and Koch, F. (2000) 'Optical absorption cross sections of Si nanocrystals', Phys. Rev. B, Vol. 61, pp.4485-4487.

21 Garcia, C., Garrido, B., Pellegrino, P., Ferre, R., Moreno, J.A. and Morante, J.R. (2003) 'Size dependence of lifetime and absorption cross section of Si nanocrystals embedded in $\mathrm{SiO}_{2}$ ', Appl. Phys. Lett., Vol. 82, No. 10, pp.1595-1597.

22 Fujii, M., Imakita, K., Watanabe, K. and Hayashi, S. (1998) 'Photoluminescence from $\mathrm{SiO}_{2}$ films containing $\mathrm{Si}$ nanocrystals ad Er: effects of nanocrystalline size on the photoluminescence efficiency of $\mathrm{Er}^{3+}$, J. Appl. Phys., Vol. 84, No. 8, pp.4525-4531.

23 Kenyon, A.J., Chryssou, C.E., Pitt, C.W., Shimizu-Ywayama, T., Hole, D.E., Sharma, N. and Humphreys, C.J. (2002) 'Luminescence from erbium-doped silicon nanocrystals in silica: excitation mechanisms', J. Appl. Phys., Vol. 91, No. 1, pp.367-374.

24 Franzò, G., Bonelli, S., Pacifici, D., Priolo, F., Iacona, F. and Bongiorno, C. (2003) 'Sensitizing properties of amorphous Si clusters on the $1.54 \mu \mathrm{m}$ luminescence of Er in Si-rich $\mathrm{SiO}_{2}$ ', Appl. Phys. Lett., Vol. 82, No. 22, pp.3871-3873.

25 Carrada, M., Gourbilleau, F., Dufour, C., Levalois, M. and Rizk, R. (2005) 'Influence of Er concentration on the emission properties of Er-doped Si-rich silica films obtained by reactive magnetron co-sputtering', Opt. Mater., Vol. 27, pp.915-919.

26 Gourbilleau, F., Rizk, R., Dufour, C. and Madelon, R. (2006) 'Effects of the si-nanocluster size on the sensitizing role towards Er ions', Euro. J. Phys. B, Vol. 51, pp.341-344.

27 Iacona, F., Pacifici, D., Irrera, A., Miritello, M., Franzò, G., Priolo, F., Sanfilippo, D., Di Stefano, G. and Fallica, P.G. (2002) 'Electroluminescence at $1.54 \mu \mathrm{m}$ in Er-doped Si nanoclusters-based devices', Appl. Phys. Lett., Vol. 81, No. 17, pp.3242-3244.

28 Lee, J., Shin, J.H. and Park, N. (2005) 'Optical gain at $1.5 \mu \mathrm{m}$ in nanocrystal Si-sensitized Er-doped silica waveguide using top-pumping $470 \mathrm{~nm}$ LEDs', J. Lightwave Technol., Vol. 23, No. 1, pp.19-25.

29 Daldosso, N., Navarro-Urrios, D., Melchiorri, M., Pavesi, L., Gourbilleau, F., Carrada, M., Rizk, R., Garcia, C., Pellegrino, P., Garrido, B. and Cognolato, L. (2005) 'Absorption cross section and signal enhancement in Er-doped Si nanocluster rib-loaded waveguides', Appl. Phys. Lett., Vol. 87, pp.261103-261105.

30 Pacifici, D., Lanzanò, L., Franzò, G., Priolo, F. and Iacona, F. (2005) 'Revealing the sequential nature of the Si-nanocluster-Er interaction by variable pulse duration excitation', Phys. Rev. B, Vol. 72, pp.045349-1-045349-6.

31 Watanabe, K., Tamaoka, H. and Fujii, M. (2002) 'Excitation of $\mathrm{Nd}^{3+}$ and $\mathrm{Tm}^{3+}$ by the energy transfer from Si nanocrystals', Physica E, Vol. 13, Nos. 2-4, pp.1038-1042.

32 Seo, S.Y., Kim, M.J. and Shin, S. (2003) 'The Nd-nanocluster coupling strength and its effect in excitation/de-excitation of $\mathrm{Nd}^{3+}$ luminescence in Nd-doped silicon-rich silicon oxide', Appl. Phys. Lett., Vol. 83, No. 14, pp.2778-2780.

33 Mann, M.M. and De Shazer, L.G. (1970) 'Energy levels and spectral broadening of neodymium ions in laser glass', J. Appl. Phys., Vol. 41, No. 7, pp.2951-2957.

34 Breard, D., Gourbilleau, F., Belarouci, A., Dufour, C. and Rizk, R. (2006) ' $\mathrm{Nd}^{3+}$ photoluminescence study of Nd-doped Si-rich silica films obtained by reactive magnetron sputtering', J. Lumin., Vol. 121, pp.209-212.

35 Ternon, C., Gourbilleau, F., Portier, X., Voivenel, P. and Dufour, C. (2002) 'An original approach for the fabrication of $\mathrm{Si} / \mathrm{SiO}_{2}$ multilayers using reactive magnetron sputtering', Thin Solid Films, Vol. 419, pp.5-10.

36 Gourbilleau, F., Dufour, C., Levalois, M., Vicens, J., Rizk, R., Sada, C., Enrichi, F. and Battaglin, G. (2003) 'Room-temperature $1.54 \mu \mathrm{m}$ photoluminescence from Er-doped Si-rich silica layers obtained by reactive magnetron sputtering', J. Appl. Phys., Vol. 94, No. 6, pp.3869-3874. 
37 Gourbilleau, F., Levalois, M., Dufour, C., Vicens, J. and Rizk, R. (2004) 'Optimized conditions for an enhanced coupling rate between Er ions and Si nanoclusters for an improved $1.54 \mu \mathrm{m}$ emission', J. Appl. Phys., Vol. 95, No. 7, pp.3717-3722.

38 Kovalev, D., Diener, J., Heckler, H., Polisski, G., Künzner, N. and Koch, F. (2000) 'Optical absorption cross section of Si nanocrystals', Phys. Rev. B, Vol. 61, No. 7, pp.4485-4487.

39 Garcia, C., Garrido, B., Pellegrino, P., Ferre, R., Moreno, J.A. and Morante, J.R. (2003) 'Size dependance of lifetime', Appl. Phys. Lett., Vol. 82, pp.1595-1597.

40 Daldosso, N., Navarro-Urrios, D., Melchiorri, M., Pavesi, L., Sada, C., Gourbilleau, F. and Rizk, R. (2006) 'Refractive index dependence of the absorption and emission cross sections at $1.54 \mu \mathrm{m}$ of $\mathrm{Er}^{3+}$ coupled to Si nanoclusters', Appl. Phys. Lett., Vol. 88, pp.161901-161903.

41 Daldosso, N., Navarro-Urrios, D., Melchiorri, M., Garcia, C., Pellegrino, P., Garrido, B., Sada, C., Battaglin, G., Gourbilleau, F., Rizk, R. and Pavesi, L. (2006) 'Er-coupled Si nanocluster waveguide', IEEE J. Sel. Top. Quantum. Electron., Vol. 12, No. 6, pp.1607-1617.

42 Garrido, B., Garcia, C., Pellegrino, P., Navarro-Urrios, D., Daldosso, N., Pavesi, L., Gourbilleau, F. and Rizk, R. (2006) 'Distance dependent interaction as limiting factor for the Si nanocluster to Er energy transfer in silica', App. Phys. Lett., Vol. 89, pp.163103-163105.

43 Wojdak, M., Klik, M., Forcales, M., Gusev, O.B., Gregorkiewicz, T., Pacifici, D., Franzò, G., Priolo, F. and Iacona, F. (2004) 'Sensitization of Er luminescence by Si nanoclusters', Phys. Rev. B, Vol. 69, pp.233315-1-233315-4.

44 Fujii, M., Imakita, K., Watanabe, K. and Hayashi, S. (2004) 'Coexistence of two different energy transfer processes in $\mathrm{SiO}_{2}$ films containing $\mathrm{Si}$ nanocrystals and $\mathrm{Er}$ ', J. Appl. Phys., Vol. 95, No. 1, pp.272-280.

45 Falconieri, M., Borsella, E., De Dominicis, L., Enrichi, F., Franzò, G., Priolo, F., Iacona, F., Gourbilleau, F. and Rizk, R. (2005) 'Probe of the Si nanoclusters to $\mathrm{Er}^{3+}$ energy transfer dynamic by double pulse excitation', Appl. Phys. Lett., Vol. 87, pp.061109-1-061109-3.

46 Watanabe, K., Fujii, M. and Hayashi, S. (2001) 'Resonant excitation $\mathrm{Of}^{3+}$ by the energy transfer from Si nanocrystals', J. Appl. Phys., Vol. 90, No. 9, pp.4761-4467.

47 Timoshenko, V.Yu., Lisachenko, M.G., Kamenev, B.K., Shalygina, O.A., Kashkarov, P.K., Heitman, J., Schmidt, M. and Zacharias, M. (2004) 'Highly efficient sensitizing of erbium luminescence in size-controlled nanocrystalline $\mathrm{Si} / \mathrm{SiO}_{2}$ superlattice structures', Appl. Phys. Lett., Vol. 84, No. 14, pp.2512-2514.

48 Kimura, T., Isshiki, H., Ide, S., Shimizu, T., Ishida, T. and Saito, R. (2003) 'Suppression of Auger deexcitation and temperature quenching of the Er-related $1.54 \mu \mathrm{m}$ emission with an ultrathin oxide interlayer in an $\mathrm{Er} / \mathrm{SiO}_{2} / \mathrm{Si}$ structure', J. Appl. Phys., Vol. 93, pp.2595-2601.

49 Jhe, J-H., Shin, J., Kim, K.J. and Moon, D.W. (2003) 'The characteristic carrier-Er interaction distance in Er-doped a-Si/SiO $\mathrm{S}_{2}$ superlattices formed by ion sputtering', Appl. Phys. Lett., Vol. 82, No. 29, pp.4489-4491.

50 Zacharias, M., Bläsing, J., Veit, P., Tsybeskov, L., Hirschman, K. and Fauchet, P.M. (1999) 'Thermal crystallization of amorphous $\mathrm{Si} / \mathrm{SiO}_{2}$ superlattices', Appl. Phys. Lett., Vol. 74, No. 18 , pp.2614-2616.

51 Kik, P.G., de Dood, M.J.A., Kikoin, K. and Polman, A. (1997) 'Excitation and deexcitation of $\mathrm{Er}^{3+}$ in crystalline silicon', Appl. Phys. Lett., Vol. 70, No. 13, pp.1721-1723.

52 Priolo, F., Franzò, G., Coffa, S. and Carnera, A. (1998) 'Excitation and non radiative deexcitation processes of $\mathrm{Er}^{3+}$ in crystalline Si', Phys. Rev. B, Vol. 57, No. 8, pp.4443-4455.

53 Suchocki, A. and Langer, J.M. (1989) 'Auger effect in the $\mathrm{Mn}^{2+}$ luminescence of $\mathrm{CdF}_{2}$ : (Mn, Y) crystals', Phys. Rev. B, Vol. 39, No. 11, pp.7905-7916.

54 Snoeks, E., Kik, P.G. and Polman, A. (1996) 'Concentration quenching in erbiul implanted alkali silicate glasses’, Opt. Mater., Vol.5, No. 3, pp.159-167.

55 Langlet, M., Coutier, C., Meffre, W., Audier, M., Fick, F., Rimet, R. and Jacquier, B. (2002) 'Microstructural and spectroscopic study of sol-gel derived Nd-doped silcia glasses', J. Lumin., Vol. 96, Nos. 2-4, pp.295-309. 